\title{
Psychological and pedagogical bases of preparation for school in preschool institutions
}

\author{
Z.V. Masaeva ${ }^{1 *}$, I.V. Abakumova ${ }^{2}$, and L.Ts. Kagermazova ${ }^{3}$ \\ ${ }^{1}$ Chechen state University, Grozny, Russia \\ ${ }^{2}$ Don state technical University, Rostov-on-don, Russia \\ ${ }^{3}$ Chechen state pedagogical University, Grozny, Russia
}

\begin{abstract}
In the modern world, there is a trend towards the demand for preparing children for school from preschool age. There are many different points of view of scientists on determining indicators of school readiness, as well as considering the understanding of school preparation from the point of view of psychological and pedagogical features. In this paper, an attempt is made to generalize existing theories of understanding school preparation, as well as an experimental study of the preparation of children in kindergarten. This issue is revealed through a developing and traditional approach. In the theoretical aspect, these approaches are disclosed and the advantages and disadvantages of the developmental and traditional approaches in preparing preschool children for school are empirically verified. The study revealed that the traditional approach does not consider personal readiness in comparison with the developmental approach. Children who studied using the traditional approach showed low results in terms of seeking help, disclosure of creative opportunities with friends, empathic feelings, control of aggression, etc. In General, summarizing the results, we can say that the traditional and developmental approaches ensure readiness for school. It should be emphasized in the context of comparative analysis that the developmental approach shows high results in comparison with the traditional approach to preparing children for school.
\end{abstract}

\section{A problem statement}

The diversity of preschool institutions is one of the main problems of modern early education. The traditional approach focuses on the transfer of knowledge and patterns of social behavior and involves teacher-oriented interaction between the child and the teacher. The developmental approach focuses on developing the child's abilities and using cultural tools, rather than just transmitting educational content. Comparing different approaches and results of preschool education can help in choosing the most appropriate one for preschool children.

\footnotetext{
**Corresponding author: ipcs-profped@yandex.ru
} 


\subsection{The objective of the work}

School readiness ensures that children start their studies with the best possible trajectory for later life. Over the past 25 years, perceptions of school readiness have changed. It is assumed that school readiness no longer corresponds to the child's chronological age or specific skills and competencies. According to the environmental approach, school readiness is multi-factor and takes into account the interests of the child, family, school and society. Children's factors include cognitive development, physical well-being, motor development, social and emotional development, forming literacy, and so on. D.

As stated in the us National initiative on school readiness indicators (2005), "Children will not enter school ready to learn unless families, schools, and communities provide an environment and experience that supports physical, social, and spiritual development $[8, \mathrm{p}$. 85].

A child's readiness for school is defined as the level of mental development necessary and sufficient for mastering the General school curriculum. Many scientists determine school readiness through the following factors: physical health, social knowledge, emotional maturity, language, cognitive development, and General knowledge $[2,4,8,11]$.

In accordance with the Russian tradition, a child's school readiness includes cognitive, personal components and voluntary regulation of behavior [1, p. 58].

The modern concept of school readiness recognizes that the development of children at an early age depends on the characteristics and relationships between children, as well as on how they develop. Early education is important for successful preparation for school. Participation in pre-school educational programs for children aged four to six years is more effective than correcting dysfunctional development at a later stage. A.K. Nisskaya argues that pre-school education brings the best result in achieving the best possible trajectory of full-fledged development [2, p. 90].

One of the most significant fundamental characteristics of modern preschool education is the recognition of the diversity of children's needs, abilities, interests and living conditions. Modern educational conditions allow preschoolers to independently choose the content, methods and trajectories of their students ' development, develop original educational programs, innovations, etc. $[3,5,7,9,16]$.

On the one hand, the growing diversity of pre-school institutions increases opportunities for creating educational environments that best meet the individual needs of the child. On the other hand, it is unclear whether there are significant differences between different approaches $[6,10]$.

The two most popular approaches - traditional and developmental-differ in their goals, the type of interaction between the child and the teacher, the learning space, and the preparation of the child for school.

The difference between the traditional approach and the developmental approach is Based on V.V. Davydov's theory of developmental education and his theory of development. The idea that learning stimulates development was expressed by L.S. Vygotsky. The essence of developmental learning is that tasks cannot be solved automatically. Children are involved in situations where they need to actively look for a tool to solve the problem. The basis of this approach is how the child is treated and how self-change is the subject of learning. The traditional approach considers the child as an object of adult learning. The approach to development considers the child as a being that requires and is capable of self-modification [13, p.31].

Thus, the developmental approach focuses on developing abilities, and using mental tools and showing initiative. This happens through the development of the child's personality. The content of education emphasizes the individual characteristics of each child. An adult encourages children to take independent actions in experimentation, problem solving, and daily routine $[7,12,14,15$,$] .$ 
The development approach promotes self-reliance, curiosity, and creativity. The traditional approach is aimed at socialization, as well as at gaining knowledge and skills. The content of education is the same for all children, regardless of their individual interests and needs, because the teacher transmits knowledge to the student through conversations, classes, games. The traditional approach involves raising obedient, compliant and disciplined children whose attention is focused on the adult. There are differences between traditional and developmental approaches to curriculum development, depending on their educational environment and the realization of their potential. It is assumed that the developmental approach provides a high level of self-regulation and awareness. Along with socialization, individualization occurs by taking into account the unique characteristics of children. The traditional approach focuses on developing social skills, promoting health, and transferring knowledge from teacher to child. All these differences can lead to different learning outcomes $[8,17]$.

\section{Materials and the results of the research}

The purpose of this study is to identify the relationship between approaches to preparing children for school in preschool institutions.

The essence of the research hypothesis is that the traditional approach and the developmental approach provide different results of school readiness. The study involved 92 preschool children (51 boys and 41 girls) aged 6 to 7 years. These children attended preschool institutions of the city of Grozny. Six psychologists and teachers were interviewed during the study. The study was conducted between 2018 and 2020.

An empirical study has shown that most children achieve a high level of cognitive readiness and can successfully interact with peers and control aggression. However, they also have difficulties in cooperating with their teacher and expressing their opinions. A comparison of the results of school readiness of traditional and developmental approaches showed that children who attended preschool with a developmental approach showed a higher level of readiness for school: they are able to ask for help, coordinate their creative intentions with their peers, empathize, and their self-awareness is higher than that of their peers who received education under the guidance of the traditional approach. In addition, they demonstrate a huge voluntary commitment to school.

Meanwhile, children who attended preschool institutions with a traditional approach showed a higher level of verbal and logical thinking. We can say that both traditional and developmental approaches provide some components of children's readiness for school. However, the development approach has better results, because it encourages children's initiative, fair attitude of the teacher to the child, and also takes into account the individual characteristics of children.

Hypotheses of the study:

Q1.are There any differences in school readiness outcomes for the developmental and traditional approaches, and what are they?

Q2.what are the benefits of a traditional preschool approach and a developmental preschool approach for children who attend them?

Research methods: method of rapid diagnostics of intellectual abilities of children aged 6-7 years" by I.S. Averina, E.I. Shabanova and E.N. Zadorina; method "Schematization" by R.I. Bardin; method "Systematization" (by N.B. Wenger); method "scale progressive matrices" by J. Raven; structured survey of the teacher; method "Educational activity" by L.I. Tsekhanskaya.

The cognitive component of school readiness of children in the traditional approach groups showed that awareness is observed in $66.7 \%$ of preschool children, which corresponds to the average level, $21.8 \%$ of participants have a high level of awareness, and 
$5.6 \%$ have a low level of awareness. $61.1 \%$ of children from the traditional approach groups have an average level of development of imaginative thinking, 22.2\% showed a high level of development, and $16.7 \%$ showed a low level.

Verbal and logical thinking is developed at a high level in $66.7 \%$ of preschool children, the average level is $27.8 \%$ and the low level is $5.6 \%$.

The cognitive component of school readiness in children from the developmental approach groups showed that $70.5 \%$ of children from the developmental approach groups have an average level of development. A high level of awareness is observed in $29.5 \%$ of cases. Low level is not detected.

Developed imaginative thinking at a satisfactory level was demonstrated by $45.5 \%$ of preschool children from the developmental approach groups. They were able to map and follow directions. The average level of acquisition of the ability to plan was demonstrated by $54.5 \%$ of respondents. The children independently navigated in visible space and successfully navigated according to plan with little help from adults. None of the subjects in this subgroup showed a low level.

$38.7 \%$ of the sample showed a high level of development of elements of verbal and logical thinking. They were able to classify objects according to the specified characteristics. $59.1 \%$ of children from the developmental approach groups have an average level of logical thinking. They are able to classify objects according to given characteristics with little help from adults. However, more precise references to the sources of their personal conclusions about the belonging of objects to a particular class caused difficulties. Only one Respondent had a low level of verbal and logical thinking. He could only classify items with considerable help from adults.

The personal component of children's readiness for school from the traditional approach groups showed that $54.5 \%$ of the total number of participants easily come into contact with adults.

Seeking help from others in difficult situations was also analyzed as an indicator of a child's social readiness for school. $56.8 \%$ of participants from the traditional approach group rarely had the opportunity to ask teachers and peers for help. These children are used to resolving conflicts with other children with the help of a teacher, but they did not use this opportunity. $40.9 \%$ of participants are used to helping others. Unwillingness and inability to help others is characteristic of only one child.

$27.3 \%$ of children had a high level of argumentation. $20.5 \%$ of participants used explanations to protect their interests. Usually, disagreements turned into quarrels or conflicts.

Self-awareness in $63.3 \%$ of children from the traditional approach groups is characterized primarily by an average level of development of representativeness about themselves and their personal abilities. These children have an idea that the most significant areas of their personal success (in particular, their ability to follow norms and rules), but usually these self-representations are poorly differentiated.

A high level of self-awareness is typical for $36.4 \%$ of the respondents in the traditional approach group. These preschoolers had a fairly complex self-representation and understanding of how they are perceived by people around them (teachers, parents, etc.).

The personal component of children's readiness for school from the developmental approach groups was shown by $74.5 \%$ of children (they were able to make contact with adults successfully). $76.1 \%$ of the survey participants are ready to ask for help and help others. $23.9 \%$ of respondents rarely sought help and provided assistance to others. There were no children who didn't do it. Coordination of a creative idea with peers is necessary for cooperation and is common for $73.9 \%$ of the group considered developing approach. $26.1 \%$ occasionally contacted their partners. There was not a single preschool child who 
was not able to cooperate and coordinate creative intentions among children using a developmental approach.

$78.3 \%$ of respondents have a high level of empathy towards their peers. Children understand the other child's emotional state and can provide emotional support. Such qualities of empathy were not typical for $17.4 \%$ of preschool children from this subgroup. $4.3 \%$ were unable to comfort or support others. $80.4 \%$ of children from the developmental approach groups were able to use arguments to defend their opinions in interaction with other children. The level of communication skills is observed in $17.4 \%$ of children, and a low level is perceived only in one Respondent. This child tends to stick to their point of view without trying to explain.

$84.8 \%$ of children have adequate self-awareness, an idea of themselves and their environment. They were able to assess their achievements and successes and were aware that some of their skills and qualities were imperfect, self-representation was quite clear.

$52.3 \%$ of children from the traditional approach groups do not show aggression towards people around them, do not resort to hostile actions or statements. $43.2 \%$ of respondents are not always ready to restrain their aggressive tendencies, but in most cases they behave friendly even in conflict situations. $4.5 \%$ of children regularly show aggression, using verbal and physical pressure on their peers as a way to cope with conflicts that were beyond their capabilities.

Control of aggressive reactions was demonstrated by $80.4 \%$ of children from the developmental approach group. Minor difficulties are experienced by $10.9 \%$ of respondents. The smallest number of children $(8.7 \%)$ were unable to control hostility towards their peers and usually found themselves at the center of conflicts.

The analysis of children's psychological readiness for school from the point of view of developing and traditional approach in groups demonstrates their essential specificity. The Mann Whitney test $(\mathrm{P}=0.05)$ was used to identify significant differences between the two groups. Comparison of the traditional and developmental approaches to school readiness showed the following: differences in the component of personal readiness for school showed that children from the groups of the developmental approach are significantly more successful in contacting adults (the average value for the developmental approach $=49.33$, for the traditional approach $=41.50, \mathrm{P}=0.08$ ).

The emotional development of children from the point of view of the developmental approach is characterized by greater empathy towards their peers (the average value for the developmental approach $=52.64$, the average value for the traditional approach $=37.18$, $\mathrm{P}=0.001$ ).

The self-awareness of children from the developmental approach groups is higher than that of children from the traditional approach groups (the average value for the developmental approach $=55.27$, the average value for the traditional approach $=34.50$, $\mathrm{P}=0.000)$.

The differences in the component arbitrary regulation of conduct school-readiness has shown that the level of voluntary regulation of behavior ("adherence to the rules and regulations of the adult") is much higher in groups developmental approach (mean value in developing the approach $=50,38$, the average value in the traditional approach $=38,06$, $\mathrm{P}=0.016)$.

The control of aggressive reactions was higher in children from the developmental approach group (the average value in the developmental approach groups $=50.37$, the average value in the traditional approach $=39.51, \mathrm{P}=0.017$ ).

The characteristics of the readiness components indicate that among the most difficult for preschoolers was the acquisition of communicative competencies: the social component of readiness, establishing a working relationship with the teacher, defending their own point of view in situations of disagreement with other children, cognitive readiness, self- 
presentation, and the ability to control their actions. Aggressive manifestations were regularly formed.

The developmental approach has more effective results of school readiness in personal components and in arbitrary behavior regulation. This approach develops the above communication skills, which can be interpreted as the effect of facilitating collaboration. Children from developmental approach groups agree to be successful in experimental activities, in creating stories, in designing, and so on. Higher self-esteem is provided in groups of developing approach by educational practices that promote children's freedom in choosing ways to solve issues that encourage originality and creativity, taking into account individual characteristics, pace and other features of the psyche. Therefore, children are faced with the need to reflect on their desires, opportunities, and limitations. Higher development of voluntary regulation of behavior contributes to the indirect development of universal skills, mastery of tools, and frequent play in groups using a developmental approach.

\section{Conclusions}

A summary of the research results shows that pre-school education provides an essential Foundation for future learning by promoting the development of cognitive abilities and skills that are important for success in later life.

This study shows the possibility of improving the quality of preschool education and demonstrates certain advantages of the developmental approach (promoting children's development), the formation of initiative, equal relations between the teacher and the child, taking into account the individual characteristics of children. This is consistent with data that suggests that it is more effective for children to complete problem-oriented tasks than to give them correct answers and complete information to study.

Children who attend preschool with a developmental approach show a higher level of personal readiness for school: they are able to seek help, coordinate creative intentions with their peers, and empathize with them. Their level of self-awareness is higher than that of their peers who study according to the traditional system. In addition, they demonstrate a high voluntary readiness for school: they easily follow the rules and instructions of adults and keep their aggressive reactions under control.

This may be due to the fact that the developmental approach is focused on the needs and abilities of preschool children, provides greater equality in the teacher-child relationship, and takes into account the individual characteristics of the child. The teacher encourages initiative and independence of children.

The traditional approach does not provide for personal and voluntary readiness as successfully as the developmental approach. Children who attended preschool with a traditional approach showed lower levels of seeking help, coordination of creative intentions with peers, empathy with peers, self-awareness, following adult rules and instructions, control of aggressive reactions, awareness and imaginative thinking. This can be explained by the lack of independence in children, the authoritarian style of communication of teachers, and the lack of playing time. Meanwhile, children showed a higher level of verbal and logical thinking. In our opinion, this is due to the fact that teachers used traditional teaching methods. Therefore, children are familiar with mathematical, verbal and logical tasks.

Summing up, we can conclude that both traditional and developmental approaches provide some components of children's readiness for school. However, the developmental preschool approach has better results, because it promotes the development of children, taking into account the interests of children and individual characteristics. 
The results show the potential of not only specially organized and targeted learning, but also the environment in the preschool organization. In addition, in the future, it is necessary to take into account not only the influence of preschool, but also educational practices in the family.

\section{References}

1. S.K. Adams, Promoting positive behavior: Guidance strategies for early childhood settings, p. 58-59 (Merrill: Pearson Education Inc., 2005)

2. A.Kh. Akhmedova, Preparing children for school as part of the implementation of the Federal state educational standard in a General education institution, Scientific Bulletin of THE state educational institution "Nevinnomyssk state humanitarian and technical Institute", 1, 65-69 (2017)

3. O.V. Alexandrov, The development mind and speech of 4-6 years kids, p. 48 (Moscow: Eksmo, 2013)

4. O.V. Didyk, Preparing children for school, p. 88-90 (In the collection: Pedagogical experience: from theory to practice, Collection of materials of the IV International scientific and practical conference (Editorial Board, 2018)

5. O.S. Kalinina, E.V. Shatalova, Preparing senior preschoolers to learn mathematics at school, Collection: High intellectual technologies in science and education, Materials of the III International scientific and practical conference, p. 155-157 (2017)

6. N.N. Kononenko, Preparing children for school in The context of the Federal state educational standard of preschool education, Science and education: new time, 6 (17), 481-487 (2016)

7. S.V. Konovalenko, Development of psycho physiological base of the speech in children of preschool age with developmental problems, p. 112 (SPb.: Childhood Press, 2012)

8. I.V. Lebedeva, E.S. Skazkina, Preparation for school of children of senior preschool age in the structure of social and pedagogical activity of PRESCHOOL Educational institutions, Collection: Innovative activity in education, Collection of articles based on the materials of the IV regional scientific and practical conference, p. 83-86 (2018)

9. E. Loretta, Bass Childhood in sociology and Society, p. 337 (Los Angeles, London, New Delhi, Singapore and Washington DC, 2010)

10. I.A. Miloslavova, The concept and structure of social adaptation, p. 24 (St. Petersburg, 2004)

11. R.R. Nasibullov, L.M. Kashapova, Z.Sh. Shavaliyeva, Conditions of Formation of Social uccessfulness of Students with Disabilities in the System of Continuous Inclusive Education on the Basis of Value Approach, International Journal of Environmental and Science Education, 10 (4), 543-552 (2015)

12. N.V. Nishcheva, The speech card of the child with the general underdevelopment of the speech from 4 to 7 years, p. 48 (SPb: Detstvo-Press, 2014)

13. F.L. Ratner, G.R. Iksanova, V.G. Ivanov, Conditions of students' adaptation to credit system of education, Obrazovanie i samorazvitie, 2 (8), 31-38 (2008)

14. T.I. Rayeva, The psycho-acmeological aspects of successful adaptation of schoolleavers to a new educational environment, p. 169 (Ivanovo, 2003)

15. M.V. Vedishenkova, E.V. Efimova, E.V. Ryabova, Student's Research Work as the Condition of Continuity of General and Professional Education, International Journal of Environmental and Science Education, 10 (4), 533-542 (2015) 
16. G.F. Yusupova, J. Podgorecki, N.G. Markova, Educating Young People in Multicultural Educational Environment of Higher Education Institution, International Journal of Environmental and Science Education, 10 (4), 561-570 (2015)

17. E.F. Zeer, Psychology of professions, p. 336 (Moscow, 2006) 